\title{
Changes in medical student attitudes as they progress through a medical course
}

John Price, David Price, Gail Williams and Raymond Hoffenberg Faculty of Medicine, the University of Queensland and (fourth author) formerly of the Faculty of Medicine of the University of Queensland

\begin{abstract}
Objectives-To explore the way ethical principles develop during a medical education course for three groups of medical students - in their first year, at the beginning of their penultimate (fifth) year and towards the end of their final (sixth) year.

Design-Survey questionnaire administered to medical students in their first, fifth and final (sixth) year.
\end{abstract}

Setting-A large medical school in Queensland, Australia.

Survey sample-Approximately half the students in each of three years (first, fifth and sixth) provided data on a voluntary basis, a total of 385 students. Results-At the point of entry, minor differences were found between medical students and first year law and psychology students. More striking were differences between male and female medical students, suggesting early socialization had a substantial impact here.

Conclusions-Results indicate that substantial changes in attitude have developed by the beginning of fifth year with little change thereafter. Gender difference persisted. Some difference in ethical attitudes were found when groups of different ethnic backgrounds were compared. The impact of a move to a graduate medical course, which gives high priority to ethics within a professional development domain, can now be evaluated.

(Fournal of Medical Ethics 1998;24:110-117)

Keywords: Attitude; medical education; undergraduate education; medical ethics; medical students; medical education; Australia

\section{Introduction}

It has been argued for some time that fostering appropriate professional attitudes and ethical practices amongst medical students is essential. ${ }^{1-5}$ However, there is little precise evidence to identify a comprehensive range of attitudes held by medical students. Some studies focus on specific issues, for example attitudes to: chemical dependency ${ }^{6}$; the elderly ${ }^{7}$ and AIDS. ${ }^{8}$ Very few investigate the broad picture. Notable exceptions are Ewan ${ }^{9}$ who examined a wide range of attitudes to social issu顿 in medicine; and Wolf $e t a l^{10}$ who investigated att tude change during medical education, across ten dimensions of an attitude profile.

There is considerable evidence that undesgraduate medical education can have a negative impact on attitudes. ${ }^{20-13}$ In general, mediegl school experience has been shown to enhane्e cynical attitudes and decrease humanitariam feelings. ${ }^{10}$ It may be argued that the emphasis 90 much undergraduate medical education has been biomedical, with little impact on encouraging broader and more liberal range of attitudes social issues in medicine. ${ }^{9}$ Myser $e t ~ a l^{14}$ argue that medical students in clinical years "... have usuaby accumulated a fairly broad, shallow and loose connected knowledge of medical ethics ... and they ... sometimes confuse 'facts' and 'values, 'opinions' and 'reasoned arguments' ...". Ho ever, there is evidence that "... attitudes can and do change during undergraduate training and cबin therefore be consciously influenced ..."."

Considerable change is currently occurring some medical curricula throughout the world. This is particularly so in Australia where three medical schools - the Flinders University of South Australia, the University of Sydney and the University of Queensland - are working in close cooperation towards the introduction of totaHy new curricula. In all three, goals, objectives and the curricula consequently developed, deliberat ey identify with the need to foster appropriape attitudes and ethical practice. For example, the University of Queensland Medical School cumriculum has a stated goal that students will be abfe to apply the highest ethical standards in the 7 practice of medicine, together with severa complementing specific objectives.

Accompanying this curricular reform has been the realisation that a comprehensive understanding of student professional attitudes and ethigl practice is not available, particularly in our on medical school, hence the exploration of attituders as described in this paper. Such exploration $\overline{\pi s}$ 
carried out knowing that ethics education will be a deliberate and integral part of the new curriculum, as has been the case in other medical schools where recent complete reassessment of medical education has occurred.

\section{Method}

THE QUESTIONNAIRE

All participants were asked to complete a 25-item questionnaire. Each question had the same format - a short stem in the form of a vignette followed by four alternative responses of which one only was to be selected.

The questions were devised by various members of the Faculty of Medicine, who were each asked to contribute a maximum of three draft items relating to their discipline. They were asked to tap attitudes rather than knowledge acquired during the process of medical education and we considered that they had done so. Two of the authors made a few alterations if it appeared that one or more of the draft responses would be unlikely to attract any support.

The final disciplinary breakdown of the 25 questions was as follows: child health 5 , clinical investigations 3 , medicine 5 , obstetrics and gynaecology 3, oncology 2, psychiatry 3, social medicine/general practice 2 , surgery 2 . The topics were wide ranging and included such diverse ethical issues as disability; HIV/AIDS; alternative medicine; bulk-billing; waiting lists, and prescription charges, to name but a few.

\section{SCORING}

For purposes of comparison we developed a numerical scoring system which would reflect student attitudes. By analysing all possible responses to the vignettes we were able to identify 23 ethical statements. Each response was matched to one or more of these statements. The 100 responses ( 25 vignettes each with 4 responses) corresponded to 127 matched statements.

For ease of analysis, the 23 statements were then grouped into 6 broad domains, the first 3 of which are components of the widely adopted four-principle approach to medical ethics (beneficence, autonomy, justice, ${ }^{15}$ ). The domain of "unacceptable or reprehensible medical conduct" did not include subsidiary statements but was treated as a single ethical statement. The 23 statements in the 6 domains are listed with the number of responses contributing to each being appended.

\section{Beneficence (B)}

1. The "best interests" of patients are always dominant and must dictate medical decisions. ${ }^{23}$
2. Even if a patient refuses treatment and fails to comply with medical regimes, a doctor must always do his or her best for the patient. ${ }^{5}$

3. Doctors must consider the interests of the family as well as those of the patient. ${ }^{6}$

\section{Autonomy (A)}

1. Consent must always be obtained before intervention. ${ }^{6}$

2. Patients have an absolute right to determine what is done to them. ${ }^{13}$

3. Patients have an absolute right to

4. Patients have a right to be told the truth. ${ }^{3}$

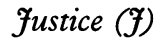

1. Public resources should never be used for selfinflicted injury or illness. ${ }^{2}$

2. Public resources should be used fairly and without prejudice. ${ }^{8}$

3. Patients should contribute something, on a fee for service basis, towards the cost of their health care. $^{2}$

4. Elderly patients have a right to full and proper health care. ${ }^{3}$

\section{Morality (M)}

1. Respect for life is an absolute principle that is paramount in medical decisions. ${ }^{6}$

2. Doctors should never chastise or "punish" a patient or be influenced by moral viewpoints.

3. Doctors should do all they can to prevent or stop any wrong or immoral practices. ${ }^{6}$

4. Patients need protection against quacks, charlatans or unprofessional medical conduct. ${ }^{2}$

\section{Doctors'rights/interests/obligations (D)}

1. Doctors must safeguard themselves against possible litigation. ${ }^{4}$

2. Doctors are normally entitled to believe patients are telling the truth. ${ }^{2}$

3. Doctors must inform the police if they suspect a crime has been committed or is being contemplated. $^{2}$

4. Doctors have an obligation to use resources properly. $^{2}$

5. Doctors have an obligation to society which can override their duty to the patient (and to each other). ${ }^{3}$ Doctors should have freedom to exercise some discretion in clinical decision-making. ${ }^{4}$

7. It is reasonable for a doctor to take a political stance in the interest of patients, individually or as a group. ${ }^{2}$

Unacceptable or reprehensible medical conduct $(U)^{13}$ Here a higher score indicates a greater degree of unacceptable or reprehensible conduct. 
Many of the responses offered clearly contained elements from more than one domain and/or related to more than one ethical statement from a particular domain.

The two medically qualified authors (JP and $\mathrm{RH})$ scored all responses independently and then collaborated so as to reach consensus. Where a response strongly affirmed an ethical statement it was allocated a score of +2 . Where there was a lesser degree of affirmation, the score was +1 . Where the response bore no relation to a particular statement the score was zero. Where the choice was somewhat opposed to a particular statement the score was -1 and, where strongly opposed, -2 .

Following is an illustration of the questions and responses used and how the scoring was done. Question:

A 35-year-old divorced woman is the mother of two children, boys aged 12 and 9 . She is a heavy user of alcohol and during severe binges neglects to feed the children, whose care is then taken over quite unofficially by a neighbour.

Responses:

a) No problem : the children aren't starving and whether she drinks or not is up to her.

b) She is unfit to have care of her children. Until she agrees to undergo an alcohol treatment programme, her children should be placed in foster care.

c) The children should be asked whether they wish to stay with their mother. If not they should be taken into care until she is deemed to be capable of looking after them.

d) She should be compelled to receive treatment for her alcohol abuse. During the period of treatment her children should be placed in foster care. If she thereafter relapses, the children should be put up for adoption.

In this instance, the scorers agreed that the drinker was the patient, her sons the "family". The responses were scored as follows:

(a) $\mathrm{B}_{1}-1, \mathrm{~B}_{3}-1, \mathrm{~A}_{1}+2$.

(b) $\mathrm{B}_{3}+1, \mathrm{~A}_{2}-2$

(c) $\mathrm{B}_{3}+2, \mathrm{~A}_{2}+2$

(d) $A_{2}-1, A_{2}-1, M_{2}-1$, Unacceptable (U)

Notice that response (c) was scored as $\mathrm{A}_{2}+2$. The difficulty here is that this response clearly exemplifies one aspect of respect for autonomy, although in this instance only as far as her sons are concerned. As her dependents, they were treated as part of her.

In order to obtain a final score for any particular statement, scores on all items, where a particular statement appeared in the scoring of any of the choices offered (ie as $+2,+1,-1,-2$, but not zero), were summated algebraically and expressed as a percentage within the corresponding range of marks, with zero $=$ no support for the stateme and $100=$ highest possible score. Negative scores indicate opposition to that statement. To give $\mathrm{A}$. as an example, six questions contained responses relating to that statement as follows: (i) $+1,-2$; (梁) -2 ; (iii) $+2,-2,-1$; (iv) -2 ; (v) +1 ; and (vi) +1 . Th恶 yields a maximum of $+5(=100 \%)$ and minimu of $-8(-100 \%)$. Zero here scores $28.6 \%$ (ie $8 / 19$ towards $100 \%$ from a percentage score of -100$)$ (5)

Regarding these percentages, an example miglat best explain one consequence of scoring as indicated: thus in the above vignette, the bes interests of the family $\left(\mathrm{B}_{3}\right)$ could be supported only at the expense of one aspect of autonom namely $\mathrm{A}_{2}$ (see (b) above). Because this occurret here (and elsewhere) it was impossible for the respondent to score $100 \%$ on both $B_{3}$ and $A_{2}$. ThE percentages have little meaning in absolute ternos but are useful for comparative purposes: for com. paring groups of respondents and for comparing the weight accorded by the questionnaire re spondents to each principle.

\section{The data collected}

In addition to the responses to the 25 questions the following information was collected: sex, age, racial origin (for example, Caucasian, Malaysia Chinese), whether either or both parents was medical practitioner and the nature of any actio religious affiliation. Students' names were not cot lected.

\section{Subjects}

The University of Queensland presently has a sì year medical course. At the time of the study, fos mal teaching in medical ethics was minimal. The first three years of the course are preclinical, the last three clinical. In the fourth year of the course students are exposed (during lectures, seminar demonstrations and clinical contact) to a variety of practising clinicians. The annual intake to the medical school is approximately 230 . Just over haly the students in each of three years (first, fifth anget sixth) provided data on a voluntary basis. The years are referred to in the text hereafter as Med Med V and Med VI respectively. Since there is no means of knowing whether those who participated differed in their attitudes from those who did noof results of the study must be interpreted accore ingly.

The numbers of medical students from varioc years who participated are as follows:

Early first year : 135

Early fifth year : 125

Late sixth year : 125 
In addition two other groups of first year students, representing a much smaller proportion than half of those enrolled in the respective courses, completed the questionnaire.

Law students $\mathrm{N}=32$

Psychology students $\mathrm{N}=58$

\section{Instructions and procedure}

Participants were asked not to consult before completing the questionnaire. Completion was not carried out during class time. The general instruction given was as follows: "For each of these vignettes, put a circle around the letter (for example, 1(a), 2(b) etc) which corresponds to the statement or course of action with which you most closely agree. We realise that none of the statements may correspond with your own attitude exactly: it is the one which is closest that we want you to indicate. There are no correct answers!"

\section{Statistical analysis}

This had several objectives:

a) to compare the three groups of first year students;

b) to examine the changes that took place over the medical course;

c) to identify ethical shortcomings;

d) to determine the influence, if any, of the demographic variables.

Analysis of variance (ANOVA) was used to compare attitudes of first year student groups, both crudely and after adjusting for age, gender, type of religion and religious activity, country of origin and whether parents were medical practitioners.

Similarly ANOVA was used to compare respondents from the three years of the medical course. Multivariate models were extended to investigate age and gender effects by each year. Supplementary t-tests were used to examine pairwise differences between groups. All computations were carried out using the statistical package SAS. ${ }^{16}$

\section{Results}

Statements have been given brief labels to assist the reader to interpret results. The percentages accorded by the medical students to each statement are shown in table 1. They have been rank ordered for Med VI. Where three or fewer questions contributed to the score the statement has been marked with an asterisk $\left(^{\star}\right)$.

It is worth noting that the Beneficence principles B1-B3 all appear fairly high on the list.
Table 1 Percentage raw scores for the three groups of medical students

\begin{tabular}{|c|c|c|c|}
\hline Statement & Med I & Med V & Med VI \\
\hline B2 (non-compliance) & 54.9 & 68.6 & 65.8 \\
\hline D6 (discretion) & 55.3 & 62.7 & 63.7 \\
\hline M4*(quacks) & 48.3 & 49.8 & 54.7 \\
\hline J4* (elderly) & 42.6 & 42.1 & 41.7 \\
\hline B3 (family interests) & 39.1 & 42.0 & 40.6 \\
\hline B1 (best interests) & 28.1 & 34.1 & 33.8 \\
\hline D3* (crime) & 28.2 & 29.3 & 32.7 \\
\hline M3 (immoral practices) & 24.6 & 22.1 & 25.9 \\
\hline Al (consent) & 24.6 & 23.7 & 25.3 \\
\hline $\mathrm{J}^{\star}{ }^{\star}$ (self-inflicted injury) & 21.0 & 10.5 & 24.8 \\
\hline A4* (truth) & 2.6 & 21.5 & 24.2 \\
\hline M1 (respect for life) & 26.6 & 20.2 & 21.0 \\
\hline J3* (contribution) & 30.6 & 20.3 & 17.5 \\
\hline A2 (patients' right to decide) & 16.3 & 19.9 & 17.3 \\
\hline D7* (political stance) & 9.8 & 11.8 & 13.1 \\
\hline A3* (confidentiality) & -8.0 & 5.6 & 9.9 \\
\hline U (unacceptable practice) & 13.4 & 8.7 & 8.4 \\
\hline D1 (litigation) & 14.5 & 10.5 & 7.7 \\
\hline J2 (resource use unprejudiced) & -1.2 & 7.6 & 4.0 \\
\hline D2* (patients truthful) & 3.9 & 4.7 & 3.7 \\
\hline D5* (obligation to society) & 25.3 & 6.6 & 1.1 \\
\hline M2 (punishing patients) & -10.0 & -1.5 & -3.8 \\
\hline $\mathrm{D} 4^{\star}$ (resources properly used) & -13.4 & -13.5 & -10.3 \\
\hline
\end{tabular}

Pairwise differences between first year student groups significant at the 0.01 level were determined, based on a comparison of raw scores. The low value for $\mathrm{p}$ was chosen because of the large number of comparisons that were made: 69 in all.

Psychology students have scores which differ from Med I students but there are no other differences: in A2 (right to decide, psychology students higher, here $\mathrm{p}<0.002$ ) and in J4 (elderly, psychology students higher, here $\mathrm{P}<0.001$ ).

Pairwise differences between the three medical student groups have been calculated using Students' " $t$ " test results. The probabilities are given in brackets, the first value indicating the Med I, Med V comparison, the second the Med I, Med VI comparison. Adjustments have been made here for the effect of all other variables.

1. Med I differs from Med V, VI but the latter do not differ from each other

a) Med I values higher :D1 (litigation, 0.041, 0.002), D5 (obligation to society, 0.0010, 0.0001 ), $\mathrm{U}$ (unacceptable practice, 0.0001, 0.0001 )

b) Med I values lower :B1 (best interests, 0.0091, 0.0009),

B2 (non-compliance, 0.0015, 0.0020),

A3 (confidentiality, 0.0004, 0.0001),

A4 (truth, 0.001, 0.001),

J2 (resource use unprejudiced, 0.0010, 0.0356),

M2 (punishing patients, 0.0047, 0.0051),

D6 (discretion, 0.0101, 0.0035)

Since almost all the differences are between Med I on the one hand and both Med V and Med VI on the other, and since probabilities multiply, all values where $\mathrm{p}<0.05$ are reported. 
2. Med V scores lower than Med I, Med VI scores. The latter two did not differ from each other: J1 (self-inflicted injury, 0.0467, 0.0137).

Multiple regression analysis examined the influence of the various demographic variables collected. Three proved unrelated to attitude in any statistically significant way: whether or not parents were medical practitioners, whether or not the respondent had an active religious affiliation and what that religious affiliation was.

As far as age was concerned, four results indicated higher scores with greater age: B1 (best interests, $\mathrm{p}=0.035$ ), $\mathrm{J} 2$ (resource use unprejudiced, $\mathrm{p}=0.008$ ), J4 (elderly, $\mathrm{p}=0.034$ ) and M1 (respect for life, $\mathrm{p}=0.0072$ ).

As far as racial origin was concerned, the data were categorised into Australian/British ( $\mathrm{n}=$ $228)$, Asian $(n=43)$ and all "other" $(n=25)$. We consider that this latter group was too small to permit further subdivision. The group included students from English-speaking backgrounds, (other than Australian/British) and other Europeans.

Racial group differences were significant ( $\mathrm{p}=$ 0.0052 ) for $\mathrm{J} 2$ (resource use unprejudiced) with Asian students achieving the lowest score, the "other" group the highest score.

The same pattern of difference was also found for J4 (elderly, $\mathrm{P}=0.0292$ ), M2 (not punishing patients, $\mathrm{p}=0.0234) \& \mathrm{D} 7$ political stance, $\mathrm{p}=$ 0.0374 .

There were also significant racial differences $(\mathrm{p}$ $=0.029$ ) for D6 (discretion) with Asians having the lowest score, and Australian/British students the highest.

Gender differences were considerable.

Females had higher scores for B1 (best interests, $\mathrm{p}=0.032$ ), B3 (family interests, $\mathrm{p}=$ 0.008 ), A2 (patients' right to decide, $\mathrm{p}=0.001$ ), A4 (truth, $\mathrm{p}=0.0096$ ), J2 (resource use unprejudiced, $\mathrm{p}=0.028$ ), J4 (elderly, $\mathrm{p}=0.0098$ ) and M2 (punishing patients, $\mathrm{p}=0.0115$ ). Females had lower scores for D1 (litigation, $p=0.0038$ ), D3 (crime, $p=0.017$ ), D4 (resources properly used, $\mathrm{p}=0.001)$ and Unacceptable practice $(\mathrm{p}=$ 0.038).

\section{Discussion}

Results obtained by comparing the first year groups are of very limited value since the participating law and psychology students were only a very small proportion of those who could have responded and could well have self-selected. However, it does seem worth comparing our findings with those of $\operatorname{Ewan}^{17}$ since that study provided data to some extent comparable with ours.
Ewan's study used the Attitude to Social Issuest in Medicine (ATSIM) scale. This scale differe substantially from our questionnaire, being con cerned with social attitudes rather than mora dilemmas. She administered ATSIM to a numbe of first year medical students at the University of New South Wales, Australia, and compared the scores with those from groups of first yea甲 students from non-medical faculties. She note\& greater conservatism in the medical students iक those areas which most closely affect the doctor's traditional role. Our results give limited support to this. For instance our first year medical students. scored lower than psychology students on $\mathrm{A} 2$, the patient's right to decide treatment.

For many students beginning medical trainingy cure may carry more appeal than care. Hence car ing for the elderly may have received less support than psychology students allotted to it. For the latter this could have been an issue of equity.

\section{Greatest shift}

One very obvious conclusion that can be draw from our results is that the greatest shift if attitudes occurs between Med I and Med V since the two later groups (V, VI) differ very little fron each other. As indicated above, exposure oca curred, particularly during the fourth year of the course, to practising clinicians in a variety of teaching settings. This appears likely to be what brought about the attitudinal changes. The last two years of clinical rotation (ie between early fifth. and late sixth year) appear to have induced little change. The only change here related to $\&$ hardening in students' attitudes to self-inflicte injury. One explanation for the failure to changi over the last two years could be that either ethical issues were not raised in the predominantly wardo teaching environment to which students wers exposed, or that the students had already move so close to their teachers in their attitudes that n⿳亠口冋 further substantial shift was possible.

What emerges when the pattern of change frorm Med I to Med V students is considered looking at the situation from the Med V perspective?

- less litigation-minded: perhaps because the mai learning environment is one in which litigation not often raised as an issue.

- more concerned with patients as needing to be accepted, warts and all so to speak, and doing one's best for them. This shows itself in highe scores on B1 (best interests), B2 (supporting the non-compliant) and $\mathrm{J} 2$ (using resources withour prejudice). The items within $\mathrm{J} 2$ made reference to a variety of groups of patients some might find leş8. than attractive - the very old, the non-complian? 
the homosexual, the hypochondriacal, the poor and the chaotic. Alongside this is a shift towards increased concern, manifesting as increased protectiveness, less likelihood of accepting an overriding obligation to society (D5) and more supportive of confidentiality (A3).

- there is quite a marked shift of support towards patients being entitled to be told the truth (A4). This might reflect a realization that doctors now frequently do this. Perhaps this was something that students entering the course had not expected.

Wolf $e t$ al $^{10}$ undertook a retrospective study of attitude change during medical education by asking students to rate themselves close to graduation with how they perceived themselves to have been on entering medical school (in this instance the Louisiana State University School of Medicine, New Orleans). No comment can be offered with respect to the two most marked perceived changes, increased cynicism and an increased concern for making money. However, these students did report an increased concern for patients and that they had become more helpful over their years of medical training.

Our findings do not accord with those of Self ${ }^{18}$ who found no statistically significant changes in "moral reasoning" based on the use of the Moral Judgment Interview. No correlations were found with age or gender. This was a much smaller study than ours, based on test results from 20 students scored in the first and final years of a four year medical course. This was an American study and the American health care system is very different from that in Australia, in a number of important respects. In Queensland, Australia, health care, for most people, centres around the provision of free hospitals.

\section{Gender difference}

De Monchy et $a l^{4}$ describe an attitude scale based on the notion of a doctor-patient continuum (the D-P scale). At one end, the physician is doctorcentred/disease-oriented; at the other patientcentred/problem-oriented. These authors found that there was a distinct later shift towards the patient end of the scale when they compared second year with final year medical students. A number of the shifts we describe above are congruent with such a change: A4, patient's right to be told the truth, D6, discretion in clinical decision-making and, in a more limited way, J2, a non-prejudicial approach to the use of resources. However, patients' right to determine what is done to them (A2), an important part of the D-P scale, did not show a significant shift over time in our study.
Let us consider now the substantial number of gender differences that emerged from the analysis. In general these differences would accord with the notion that women, compared with men, are more "caring". The concept of caring, encountered more frequently in the nursing than in the medical literature needs to be defined. According to Fry, ${ }^{19}$ the masculine theorizing of medical ethics, giving priority to principles over people, ${ }^{20}$ is not grounded as is nurse-caring in "the patient's status as a human being". McBride, ${ }^{21}$ in similar vein, defines caring as a way of being for people which is responsive rather than judgmental or hierarchical. More specific to our findings is what Aroskar has to $\mathrm{say}^{22}$ : patients are identified as the exclusive choice makers ... advocacy means carrying out the patient's wishes. Justice is inherently impartial but the ethics of caring do not operate in that way: they are necessarily partial. Nelson ${ }^{23}$ puts this well: Can one ask "a mother to love her child specially, dearly, and singly but to be careful not to love the child more than any other child". Patient partiality in our female medical students is what many of the gender differences listed above have in common.

\section{Early socialization}

The nursing literature is written from a nursing viewpoint which seems to ignore the fact that many nurses are male. Likewise, of course, many doctors are female. Whether female doctors practise differently from men then becomes a relevant question. If they do, has the increased number of women in medical school and medical practice changed the way their male colleagues practise and, if so, has the change been in the direction of caring, a much more difficult question to answer.

Do female doctors practise differently? Maheux et $a l^{4}$ cited evidence from a number of sources that they do. They are more concerned with interpersonal and psychosocial aspects of patient care than males are, differences being explained by the different way males and females are socialized from early childhood to adulthood.

How critical is socialization to the development of an ethical framework? We have examined the Med I data to see what gender differences were in evidence at the beginning of medical education. This confirms gender effects (in the same direction as indicated above) for the following: B1 (best interests), A2 (patients' right to decide), A4 (truth), J2 (resource use unprejudiced), M2 (punishing patients), and $U$ (unacceptable ... conduct). Early socialization is therefore important.

Fennema et $a l^{5}$ reported that humanness was seen by $43 \%$ of patients as gender-neutral but that $43 \%$ saw it as more characteristic of the female 
physician, while only $12 \%$ viewed it as more strongly characteristic of the male. Female physicians were perceived as more human than male physicians. Women medical practitioners were preferred for depression and family consultations. Gray, ${ }^{26}$ reviewing a number of studies, concludes that "the qualities which women doctors tend to have, and which women in general tend to have, correspond with the qualities patients desire in a good doctor". Again, "communication is easier, more time is given, drugs are less frequently dispensed and women patients are treated more seriously if the doctor is a woman". However, what the findings of our study suggest is the likelihood that our students, as practitioners, will make gender-specific ethical decisions.

An important set of results in this study indicates significant differences between ethnic groups for five ethical principles. For each of these principles Asian students achieved the lowest score and with one exception (D6, discretion) "the other group" the highest score.
$\mathrm{J} 2$ (resource use unprejudiced)
$\mathrm{J} 4$ (elderly)
M2 (not punishing patients)
D7 (political stance)
D6 (discretion)

In general terms, these data suggest Asian students in the sample were more authoritarian, prejudiced, rigid and less supportive of patients' rights. However, there is little evidence in the literature to support these trends. Paris ${ }^{27}$ in a large study of fourth year Californian medical students found that whites, compared with Asians were found to hold significantly more positive attitudes towards people with physical disabilities. Shokoohi-Yekta and Retish $^{28}$ report significant differences between Chinese and American male students towards mental illness, with Americans being more positive. A small number of studies ${ }^{29} 30$ deplore the lack of student sensitivity generally to cultural differences in patients, and call for programmes to address this need.

There is a need for more research to identify precisely the impact of ethnicity on ethical practice. The outcomes of such research could have major implications for teaching and learning where ethical/attitudinal issues are given emphasis.

\section{Conclusion}

This paper indicates that substantial changes towards ethical issues occur during the course of medical education despite a paucity of education focusing on these matters.
In the new course, which begins at this medica school in 1997, ethics education is to be giver specific and extensive attention: it is one of four domains, and is entitled "Ethics, Personal an Professional Development". We are now in position, using our questionnaire, to evaluate thछ learning outcomes relating to this domain.

fohn Price MD, FRCP, FRCPsych, FRANZCP, $i$ ș Professor of Psychiatry in the Faculty of Medicine, the University of Queensland. David Price, $B A, M E d \overrightarrow{\vec{L}}$ $P h D$, is Senior Lecturer in the Academic Staff Devel opment Unit, the Queensland Medical Education Centre, Faculty of Medicine, the University of Queensland. Gail Williams, MSc (London $\mathcal{E}$ Qld) $P h D$, is an Associate Professor in the Tropical Health Program, Faculty of Medicine, the University of Queensland. Raymond Hoffenberg, MD, FRCP, was formerly a Visiting Professor in Medical Ethics in the Faculty of Medicine, the University of Queensland.

\section{References}

1 Sanson-Fisher R, Maguire P. Should skills in communicating with patients be taught in medical schools? Lancet 1980 ; ii:523

2 Knight JA. Doctor-to-be: coping with the trials and triumphs of medical school. New York: Appleton-Century-Crofts, 1981.

3 Delaney B, Kean L. Attitudes of medical students to the teachen ing of medical ethics. Medical Education 1988;22: 8-10.

4 de Monchy C, Richardson R, Brown RA, Harden RM. Measure ing attitudes of doctors: the doctor-patient (DP) rating. Medicat Education, 1988;22:231-9.

5 Lovett LM, Seedhouse D. An innovation in teaching ethics toิ medical students. Medical Education 1990;24,1:37-41.

6 Oldham SB, Sipe F. An experiential training program and medi cal students' attitudes toward patients with chemical depend-. ency. Academic Medicine 1990; 65,6:421-2.

7 Miller MD, Oppenheimer KC, Melcher R. Medical studen attitudes toward elderly patients: effects of social attractiveness Family Medicine 1990;22,1:29-32.

8 Bernstein CA, Rabkin JG, Wolland H. Medical and dental stw. dents' attitudes about the AIDS epidemic. Academic Medicing 1990;65,7:458-60.

9 Ewan C. Social issues in medicine: a follow-up comparison of senior year medical students' attitudes with contemporaries iD non-medical faculties. Medical Education 1988;22,5:375-80.

10 Wolf TM, Balson PM, Faucett JM, Randall HM. A retrospectiv study of attitude change during medical education. Medica Education 1989;23:19-23.

11 Weinstein HM. A committee on well-being of medical students and house staff. Fournal of Medical Education 1983;58:373-81.

12 Muller S, (Chairman). Physicians for the twenty-first centur Report of the Project Panel on the General Professional EducaN tion of the Physician and College Preparation for Medicinew Fournal of Medical Education 1984;59:1-208.

13 Rosenberg DA, Silver HK. Medical students' abuse: an unnecessary and preventable cause of stress. Fournal of the Americd? Medical Association 1984;251:739-42.

14 Myser C, Kerridge IH, Mitchell KR. Ethical reasoning an£ decision-making in the clinical setting: assessing the process.. Medical Education 1995;29:29-33.

15 Beauchamp T, Childress J. Principles of biomedical ethics. Ne@ York: Oxford University Press, 1989.

16 SAS Institute Inc. $S A S / S T A T$ user's guide [version 6 , 4th ed, vo 1]. Cary, North Carolina, USA. SAS Institute Inc, 1989: 943. (D)

17 Ewan CE. Attitudes to social issues in medicine: a comparison of first-year medical students with first-year students i non-medical faculties. Medical Education 1987; $21: 25-31$

18 Self DJ, Schrader DE, Baldwin Jr DC, Wolinsky FD. The mor $\$$ development of medical students: a pilot study of the possib influence of medical education. Medical Education 1993;27:26-34

19 Fry ST. The role of caring in a theory of nursing ethics. Hypat 1989;4,2:88-103. 
20 Kohlberg L. Essays on moral development: volume II, the psychology of moral development. New York: Harper and Row, 1984.

$21 \mathrm{McBride} \mathrm{AB}$. Knowledge about care and caring: state of the art and future development. Reflections 1989;15,2:5-7.

22 Aroskar MA. Caring: another side. fournal of Professional Nursing 1991;17,1:3.

23 Nelson HL. Against caring. The fournal of Clinical Ethics 1992; 3,1:8-15.

24 Maheux B, DuFort F, Lambert J, Berthiaume M. Do female general practitioners have a distinctive type of medical practice? Canadian MAF 1988;139:737-40.

25 Fennema K, Myer DL, Owen N. Sex of physicians: patients' preferences and stereotypes. Fournal of Family Practitioners 1990; 30:441-6.
26 Gray J. The effect of the doctor's sex on the doctor-patient relationship. Fournal of the Royal College of General Practice 1982;32: 167-9.

27 Paris MJ. Attitudes of medical students and health-care professionals toward people with disabilities. Archives of Physical and Medical Rehabilitation 1993;74,8:818-25.

28 Shokoohi-Yekta M, Retish PM. Attitudes of Chinese and American male students towards mental illness. International fournal of Socical Psychiatry1991;37,3:192-200.

29 Lum CK, Korenman SG. Cultural-sensitivity training in US medical schools. Academic Medicine 1994;69,3:239-41.

30 Eisenbruch $M$. Medical education for a multicultural society. Medical fournal of Australia 1989;151,10:574-6, 579-80.

\section{News and notes}

\section{Health Care Issues in Pluralistic Societies}

A European Bioethics Seminar: Health Care Issues in Pluralistic Societies, will be held in Nijmegen, the Netherlands from 3-7 August, 1998. The seminar is organised by the International Programme in Bioethics Education and Research. Speical attention will be paid to European traditions in health care ethics. All lectures and plenary sessions will be held in English.
For further information please contact: B Gordijn, PhD, Catholic University of Nijmegen, 232 Dept of Ethics, Philosophy and History of Medicine, PO Box 9101, $6500 \mathrm{HB}$ Nijmegen, the Netherlands. Telephone: (31) 24-3615320; fax: (31) 24-3540254. E-mail: b.gordijn@efg.kun.nl. Internet site: http://www.azn.nl/ fmw/maatschp/bioethl.htm

\section{News and notes}

\section{Human Rights and the Duty to Rescue}

A one-day conference, Human Rights and the Duty to Rescue, will be held at the University of Manchester, England on Thursday September 3rd, 1998.

Speakers will include:Professor Jonathan Glover, Professor Hillel Steiner, Professor Alexander McCall Smith, Professor John Harris and Professor Raymond Plant.
For futher information please send your name and postal address to: Dr John Hostler, Director of the School of Philosophical Studies, Room C1.48, Humanities Building, University of Manchester, Oxford Road, Manchester M13 9PL. 